\title{
ON THE EXPLANATION OF SCHOOLING, OCCUPATION AND EARNINGS: SOME ALTERNATIVE PATH ANALYSES**
}

\author{
BY
}

\section{GEORGE PSACHAROPOULOS AND JAN TINBERGEN*}

\section{INTRODUCTION}

In recent years a happy marriage has taken place in the social sciences: that between education sociology and education economics. Up to the late sixties sociologists' efforts were concentrated on exploring occupational status (e.g. see Blau and Duncan 1967), whereas economists aimed at explaining earnings abstracting from occupation and other background characteristics (e.g. see Mincer 1970). The publication of Jencks' (1972) Inequality, however, could be cited as a major contribution that brought various approaches together in an effort to understand the education-ability-occupation-earnings nexus.

Recent empirical analyses in this area use recursive (path) models where the sequence of causation follows the natural chronological order. ${ }^{1}$

$$
\left(\begin{array}{c}
\text { Family } \\
\text { background }
\end{array}\right) \rightarrow\left(\begin{array}{c}
\text { Intellectual } \\
\text { ability }
\end{array}\right) \rightarrow\left(\begin{array}{c}
\text { Educational } \\
\text { attainment }
\end{array}\right) \rightarrow\left(\begin{array}{c}
\text { Occupational } \\
\text { status }
\end{array}\right) \rightarrow\left(\begin{array}{c}
\text { Labour } \\
\text { earnings }
\end{array}\right)
$$

In this paper we explore two questions related to the above sequence. The first question is: What is the role of occupational status in the earnings and educational attainment process? The second question is: How valid is the treatment of earnings as the ultimate dependent variable in the above process? The two questions are analysed empirically by using data from the British General Household Survey.

Section 2, below, presents the conventional path model. Section 3 compares the results with some material for other countries. Section 4 discusses the role of occupation in alternative path models. Section 5 revises the order of causation

\footnotetext{
* London School of Economics and Erasmus University, Rotterdam.

** We are grateful to the British Office of Population Census and Surveys for making available to us the data from which the UK results reported in this article were obtained.

1 Intellectual ability could be placed at the same time period as family background if one had a pure genetical IQ measure.
} 
and treats earnings as an independent, aimed-at, variable in the above sequence. Section 6 shows the results of attempts to introduce non-linear and interaction terms; section 7 attempts to introduce an additional number of dummy variables. The last section (8) presents some concluding remarks.

\section{THE TRADITIONAL PATH MODEL}

Following the work of Duncan, Jencks and others we first fit a four equation recursive model of the following kind:
(1) Ability:
$A=f($ Family background: $F)$
(2) Schooling:
$S=g(F, A)$
(3) Occupation: $O C C=h(F, A, S)$
(4) Earnings:
$Y=i(F, A, S, O C C)$

The sample consists of 5,578 male employees in the UK, aged 25-64. Those under 25 years old were excluded from the analysis in order to eliminate most of the age effect and thus avoid the introduction of additional age (or experience) variables.

Family background $(F)$ is measured on the Goldthorpe and Hope (1974) scale of the respondent's father occupation. Schooling $(S)$ is measured by the respondent's number of years of education completed. Ability $(A)$ is measured by the number of O-level passes, i.e. the number of passes obtained at the examination for the General Certificate of Education, Ordinary Level. This is a national examination taken at the age of 16 . The number of such passes is considered a proxy for ability. Occupation $(O C C)$ is also measured by the Goldthorpe and Hope scale. Earnings $(Y)$ is measured by the respondent's annual earnings from employment.

The means, standard deviations and zero-order correlation matrix between these (and other) variables (used later in this paper) appear in Appendix $1{ }^{2}{ }^{2}$

Display 1 shows the resulting model. All coefficients are in normalised (beta) form (i.e., the variables have been transformed so as to make their average equal to zero and their standard deviation equal to 1 ). The $t$-ratios are not reported as they all are well in excess of 2.0 .

There are several features worth noting in this display. First, the level of educational attainment is better explained (as judged by the higher $R^{2}$ ) by family background and ability than occupation or earnings are. Second, the direct effect of family background on earnings is very small (path coefficient equal to .036). On the other hand family background is much more important in determining the respondent's occupation, the latter in turn strongly determining 
earnings. Thus family background operates on earnings mainly in an indirect (via occupation) way. The same result holds for schooling, although here both the direct and indirect effects are substantial.

\section{Equations}

\begin{tabular}{|c|c|}
\hline & $R^{2}$ \\
\hline$A=.242 F$ & .059 \\
\hline$S=.164 F+.526 A$ & .345 \\
\hline$O C C=.113 F+.183 A+.221 S$ & .164 \\
\hline$Y=.036 F+.137 A+.174 S+.3420 C C$ & .279 \\
\hline
\end{tabular}

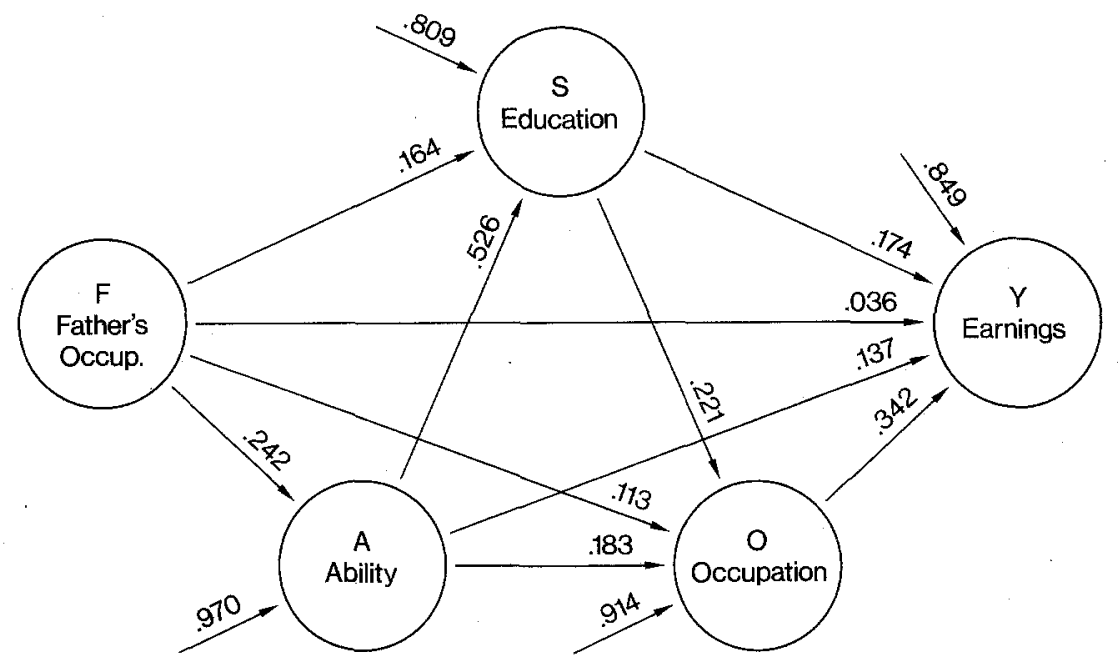

Display 1 The basic path model

\section{COMPARISONS WITH RESULTS OBTAINED BY OTHER AUTHORS}

As stated, our analysis is not the first of its sort. Actually, after Jencks's at least three similar attempts preceded ours. These refer to the United States (Bowles and Nelson, 1974), Sweden (Bulcock, Fägerlind and Emanuelsson 1974) and the Netherlands (Dronkers and De Jong, 1978). In addition one of us has used Bowles's publication in order to estimate a few alternative equations to be discussed later (Tinbergen, 1976).

The various studies did not use the same variables as in the present article bearing on Britain. The Swedish study did not use 'father's occupation' se- 
parately, and the Dutch study 'father's income.' On the other hand, all three had data on respondents' IQ or other 'ability' variable at two ages, roughly at 10 and 20 years of age. Moreover the American and the Dutch studies had data for age groups of ten year spans for schooling, occupation and income of respondents.

The notations used were different and Table I provides the reader with the necessary conversion information. Table II shows in the most condensed form the estimated equations of the various studies, including the basic path analysis of the present article, due to one of us, Psacharopoulos. Wherever several age groups had been investigated we chose the 45-54 year group for the USA and the 51-60 year group for the Netherlands, both characterised by the subscript 5 . We felt justified to do so since in most cases no systematic differences between the regression coefficients of age groups were found. One exception was the impact of schooling on occupation found by Bowles and Nelson, where it was higher the younger the group considered, the range in coefficients being from .643 to .452 . In

TABLE I - NOTATIONS USED BY AUTHORS QUOTED

\begin{tabular}{llllll}
\hline Author(s) & BN & BFE & DJ & BNT & PsT \\
Schooling & $S$ & EDUC & 5 & $S$ & $S$ \\
Schooling, father & $F S$ & $F A T H E D$ & 1 & $E$ & $S_{f}$ \\
Occupation status & $O$ & OCC 71 & $7-11$ & $O$ & $O C C$ \\
Occupation status father & $F O$ & & 2 & & $F$ \\
Socio-economic Background & SEB & SES 38 & & $B$ & $B$ \\
$\begin{array}{l}\text { Ability or IQ, childhood } \\
\text { Ability or IQ, 20 years old }\end{array}$ & $C I Q$ & $I Q 38$ & 4 & $Q$ & $Q C$ \\
$\begin{array}{l}\text { Genotype IQ } \\
\text { Income, annual }\end{array}$ & $A I Q$ & $I Q 48$ & 6 & & $A$ \\
Income, weekly & $G$ & & & & $Y$ \\
Nat. log. Income, annual & $I$ & INC 71* & $12-16$ & & $Y / W$ \\
Nat. log. Income, father & & & & & $L_{n} Y$ \\
Nat. log. Income per & & LOGINC & & & \\
$\quad$ cap., family & & & & $P$ & $y_{f}$ \\
(father's) Family Size & & REALI* & & & $n$ \\
\hline
\end{tabular}

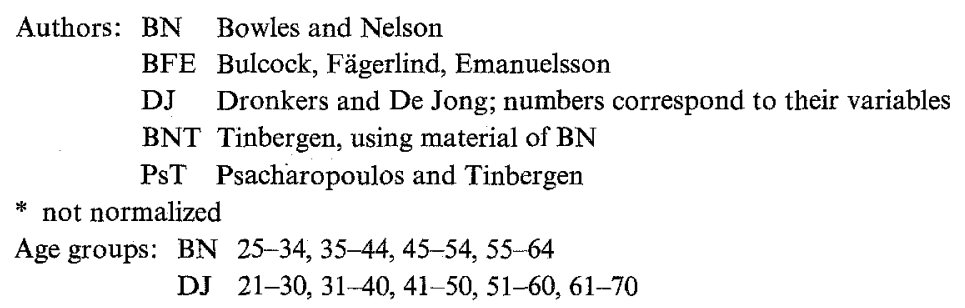


Table II the figure .530 is shown. Another exception are the same coefficients in the other equations for schooling based on the Bowles-Nelson material.

Some further features of the comparative table seem to be the following:

(i) All $R^{2}$ 's obtained for equations (1), the 'explanations' of ability (either around 10 or around 20 years of age) with the aid of data about parents, are low: such data explain a very small part of ability's variance. The only exceptions are the explanations, by the Dutch and the Swedish material, of ability at age 20 by ability at age 10, (Equations $1 \mathrm{~A}$ ). In the Dutch case schooling has an insignificant negative impact, in the Swedish case a significant positive impact, and a slight negative impact of an interaction term in schooling and childhoold IQ.

(ii) Equations (2) 'explaining' schooling show $R^{2}$ 's ranging from .345 to .522 . About the same level of $R^{2}$ as for Britain is found in the Swedish study, but even higher values are found for the United States by Bowles and Nelson (.463) as well as by the inclusion of $A$. Values up to .63 are found, however, by the inclusion of occupation as an independent variable, an alternative we are going to discuss later.

(iii) Equations (3) with occupation as the dependent variable show large differences in $R^{2}$. Using the same independent variables, father's occupation, schooling and ability, our British material only explains $16.4 \%$ of the variance in occupation, compared with 48.6 per cent for the American material. The Dutch material, using father's education instead of occupation, even explains 73 per cent.

(iv) The occupation equation performs better than the various income equations. British and American material attains at most an explanation of one-third of the variance. The Swedish material, using two interaction terms, reaches one half, and the Dutch material 63 per cent. Contrary to what the human capital school claims, logarithms don't improve the $R^{2}$. Weekly incomes perform better than annual.

Equations (3) and (4) marked PsT refer to the present paper and will be discussed in some more detail, including a comparison with Equations (3) and (4) marked BNT.

\section{THE ROLE OF OCCUPATION}

It has been traditionally assumed, as in the model presented in Section 2, that schooling is an antecedent variable (i.e., precedes occupation). However, as 


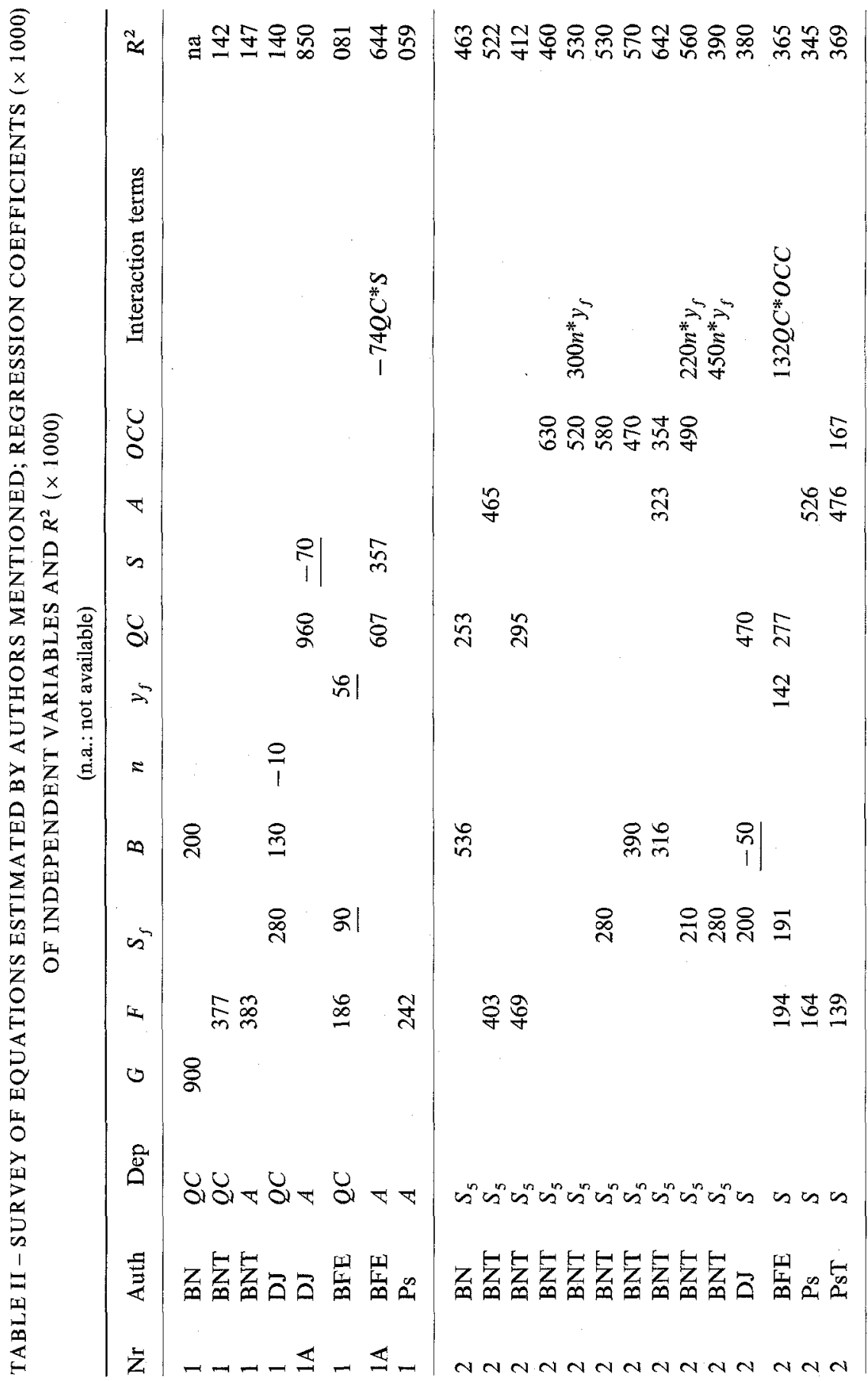


윤원유욤

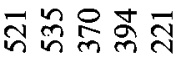
$\stackrel{\sim}{\sim} \infty$

ño

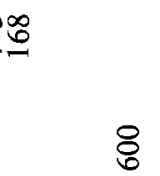

트 $\cong$ 조

(1)

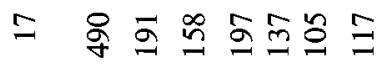

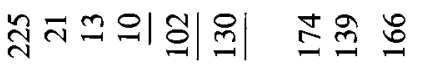
$\infty$ in

ลิ<smiles>[SiH]=[SiH]</smiles>

ठํ ஓ्त

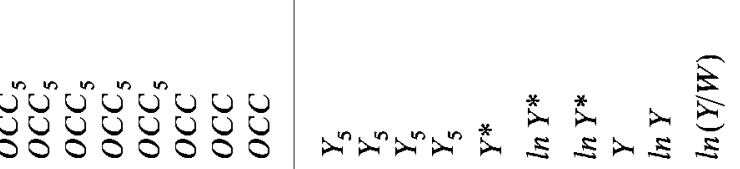

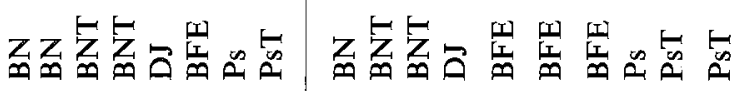
mmmmmmmm 
suggested by Tinbergen (1976) the direction of causation might be the other way round: namely, people aim at a certain occupation and acquire the necessary level of schooling in order to enter this occupation.

The alternative path model fitted in Table III assumes that family background determines the level of measured ability and occupational aspirations of the respondent. Schooling follows at a later stage (3rd equation) and the model explains 37 per cent of its variation. The four variables in turn explain about 23 per cent of relative (logarithmic) income which, of course is not different from the basic model. It is interesting to note that in this formulation family background becomes an insignificant variable.

Whereas the results obtained by this working hypothesis do not constitute, for the British material, much of an improvement - in fact, the variance of schooling explained only increases from 34.5 to 46.9 per cent - the explanation of schooling variance in the American material can be raised from 46 to around 60 per cent. This is a reason why we pursued this alternative. It is admitted, though, that the explanation of occupation becomes worse. For the British material Table III summarises the results obtained.

As the variance of occupational status explained in this alternative is less than 5 per cent, we tried to improve this explanation by introducing as further explanatory variables ability and schooling, which led to

$$
O C C=.111 F+.183 A+.221 S, \quad R^{2}=.164
$$

There is no necessity to leave $S$ out; all that we now try to verify is the working hypothesis that occupational status (aimed at) and schooling are mutually dependent or, in plain language, that they are intertwined. In econometric models this is a frequently made assumption. As a consequence of this assump-

\begin{tabular}{|c|c|c|c|}
\hline \multicolumn{4}{|c|}{ SCHOOLING } \\
\hline & & Equations & $R^{2}$ \\
\hline \multicolumn{3}{|c|}{$A=.242 F$} & .059 \\
\hline \multicolumn{3}{|c|}{$O C C=.220 F$} & .048 \\
\hline \multicolumn{3}{|c|}{$S=.139 F+.167 O C C+.476 A$} & .369 \\
\hline \multicolumn{3}{|c|}{$\ln Y=.012 F^{*}+.346 O C C+.105 A+.139 S$} & .229 \\
\hline \multicolumn{3}{|c|}{$Y=.036 F+.342 O C C+.137 A+.174 S$} & .279 \\
\hline $\ln \left(\frac{1}{T}\right.$ & \multicolumn{2}{|c|}{$=.037 F+.3470 C C+.117 A+.166 S$} & .265 \\
\hline
\end{tabular}

\footnotetext{
* Coefficient not significant.
} 
tion, however, $S$ and $O C C$ become simultaneously dependent on $F$ and $A$. This implies that only the reduced forms $S(F, A)$ and $O C C(F, A)$ can be estimated by Ordinary Least Squares. The above reported equation for $O C C$ can only give information on the maximum attainable $R^{2}$.

\section{REVERSING THE SCHOOLING - EARNINGS RELATIONSHIP}

It has long been observed that earnings and education correlate positively. The usual theory behind this association is that schooling increases the productivity of the individual and thus enhances his earnings. On the basis of this theory the observed correlation is turned into a causation model

$$
Y \leftarrow f(S)
$$

which has been incorporated in the previous path analyses.

What we would like to do in this section is to experiment with an alternative theory: It is 'earnings aimed at' that represents the independent variable, adding the assumption that actual earnings are those aimed at. ${ }^{3}$ Schooling follows as a behavioural response of the individual to achieve his target earnings. Thus, the model to be fitted now becomes

$$
S \leftarrow g(Y)
$$

Of course in a single equation model the reversal of causation will not alter the fit. But one can assume that a given family background sets given target earnings. This is perhaps not so much because of the individual's response but because of that of his family. Rich parents with high $F$ score set a high $Y$ target for their children. Thus, they push them to acquire as much schooling as they suspect (from casual observation) that would lead to the target earnings later in the son's life.

This leads to a recursive model of the form

$$
\begin{aligned}
& Y=f(F) \\
& S=g(F, Y)
\end{aligned}
$$

3 It should be noted that this is a heroic assumption. Of course we would have liked to use father's earnings, but this information was not available in the sample. 
Furthermore, one could use occupation as an intervening variable between the $Y$ target and $S$. Table IV shows the results obtained along these lines where $Y$ is considered as given, perhaps determined by $F$.

The results under (b) are now not better, but slightly worse, than those obtained under (a). In both cases the $R^{2}$ obtained without using $A$ or $F$ are considerably worse than those including these two variables. The inclusion of $Y$, does not, however, change the results of the basic path model dramatically ( $c f$. Section 2).

For completeness' sake Table V shows the alternative path model corresponding to the new role given to $Y$, without and with occupation as an intervening target of schooling completed.

\section{NON-LINEAR AND INTERACTION TERMS}

The next problem considered was the improvements to be obtained by the introduction of non-linear and interaction terms, (Table VI).

The $R^{2}$ was only affected slightly more than marginally in the occupation equation in the basic path model; here a curvilinear influence of schooling on

TABLE IV - SCHOOLING AS A FUNCTION OF TARGET INCOME AND OTHER VARIABLES

(a) Target is Annual Earnings

Equations $\quad R^{2}$

$S=.383 Y \quad .147$

$S=.208 Y+.491 A$

$S=.158 Y+.466 A+.129 O C C$

$S=.148 Y+.444 A+.112 O C C+.130 F \quad .385$

$S=.279 Y+\quad .2290 C C \quad .189$

(b) Target is Weekly Earnings

$\begin{array}{ll}\quad \begin{array}{l}\text { Equations } \\ S=.304\left(\frac{Y}{W}\right)\end{array} & R^{2} \\ S=.159\left(\frac{Y}{W}\right)+.521 A & .093 \\ S=.118\left(\frac{Y}{W}\right)+.481 A+.1560 C C & .343 \\ S=.108\left(\frac{Y}{W}\right)+.457 A+.1380 C C+.132 F & .363 \\ S=.207\left(\frac{Y}{W}\right)+.2860 C C & .165\end{array}$


(a) Excluding Occupation

$\begin{array}{lc}\quad \text { Equations } & R^{2} \\ A=.242 F & .059 \\ Y=.115 F+.330 A & .141 \\ S=.142 F+.463 A+.190 Y & .376\end{array}$

(b) Using Occupation as an intervening variable

\begin{tabular}{|c|c|}
\hline Equations & $R^{2}$ \\
\hline$A=.242 F$ & .059 \\
\hline$Y=.115 F+.330 A$ & .141 \\
\hline$O C C=.104 F+.175 A+.375 Y$ & .253 \\
\hline$S=.130 F+.444 A+.148 Y+.112 O C C$ & .386 \\
\hline
\end{tabular}

occupation is found, where the marginal effect of schooling becomes zero for $S$ $=.66$ or, transforming back to original units, 11.9 years of schooling.

Again, as observed before, these equations contain an unknown OLS bias ( $c$. end of section 4). The point we make is that the $R^{2}$ is hardly improved. The only interaction effect found to exist was one of schooling and ability on income, interestingly negative:

$$
Y=.245 S-.047 S^{2 *}+.288 A-.168 \cdot S+.034 F+.338 O C C, \quad R^{2}=280
$$

7 IMPACT OF ADDITIONAL (DUMMY) VARIABLES

A last series of runs was done in which some further characteristics of the sample population were added, usually reflecting a situation where only one of two

\section{TABLE VI - NON-LINEAR RELATIONSHIPS}

( $R^{2}$ obtained without quadratic terms shown in parentheses)

\begin{tabular}{cc}
\hline Equations & $R^{2}$ \\
$Y=.034 F+.132 A+.337 S-.161 S^{2}+.3400 C C$ & $.280(.279)$ \\
$\left.S=.207 Y+.643 A-.155 A^{2}=1.88\right)$ & $.359(.357)$ \\
$S=.159\left(\frac{Y}{W}\right)+.681 A-.165 A^{2}$ & $.344(.343)$ \\
$O C C=.103 F+.160 A+.972 S-.742 S^{2}$ & $.179(.164)$ \\
\hline
\end{tabular}

* Non-significant. 
TABLE VII-IMPACT OF A NUMBER OF ADDITIONAL (DUMMY) VARIABLES ON $L N Y$ AND $L N(Y / W)$

\begin{tabular}{|c|c|c|c|}
\hline Dependent: & $\ln Y$ & $\ln \left(\frac{Y}{W}\right)$ & $\ln \left(\frac{Y}{W}\right)$ \\
\hline$S$ & .142 & .174 & .208 \\
\hline OCC & .327 & .331 & .313 \\
\hline$F$ & $.017 *$ & .040 & .046 \\
\hline$A$ & .103 & .116 & .118 \\
\hline Apprentice & $-.011 *$ & $-.156^{*}$ & $-.017^{*}$ \\
\hline Urban Resident & .036 & .040 & .043 \\
\hline Married & .099 & .114 & .098 \\
\hline Coloured & -.086 & -.083 & -.079 \\
\hline British & $-.025^{*}$ & -.028 & -.017 \\
\hline Poor Health & -.161 & -.090 & -.083 \\
\hline Experience, years of, $(E x)$ & & & .930 \\
\hline$E x^{2}$ & & & -.967 \\
\hline$R^{2}$ & .271 & .293 & .330 \\
\hline$R^{2}$ excluding additional variables & .229 & .265 & .265 \\
\hline
\end{tabular}

* Coefficient not statisticaliy significant.

possibilities can exist, represented by dummy variables $(0,1)$. Table VII shows the results, and compares the $R^{2}$ obtained with the $R^{2}$ obtained without the additional variables. ${ }^{4}$ There is a clear improvement to be noticed, ${ }^{5}$ but it is evident that important non-specified factors remain tó be searched for if we want to explain the major portion of variance in the dependent variable.

\section{CONCLUSION}

In this article several objectives have been pursued; let us briefly sum up their nature and the (provisional) results attained.

In Section 2 we estimated the path coefficients of the traditional path analysis linking family background, ability, schooling, occupation and earnings with the aid of the very large sample of the British General Household Survey of 1972. The picture obtained is not glaringly different from what has been estimated for other

4 The 2 to 3 percentage weekly earnings advantage of those who are not British in the sample might be explained by the fact that these foreigners work for multinational corporations, a factor that has not been measured by our variables.

5 The $R^{2}$ differences before and after the addition of the new variables are highly significant according to the $F$-test. 
countries (the USA, Sweden and the Netherlands), although none of the coefficients is strikingly stable and very few of the $R^{2}$ surpass 50 per cent.

In sections 3 and 4 alternative roles are given to occupation and income, namely of targets aimed at instead of results attained by family background and schooling completed. These alternative roles do not bring significant improvements, respectively, in the explanation of schooling equations of the British material. Using the American data, the explanation of schooling is considerably improved assuming the alternative role of occupation.

Sections 5 and 6 attempted to improve the basic path model by the introduction of non-linear and interaction terms and of some additional (dummy) variables. Here again, the improvements are modest at best. With one exception (the impact of schooling on occupation) the linear forms in the basic model appear to be sufficient.

We may finish with one more far-reaching question. In a forthcoming Dutch study explanatory variables representing more typically labour market specifications of three types have been used in order to explain incomes. This Dutch material, admittedly for much smaller samples (Berkouwen, Hartog and Tinbergen, 1978), explains considerably larger portions of income variance. The estimators used in this study are education required alongside actual education and one or more non-cognitive more precisely specified capabilities required to do the job held properly. The impression is that variables more specific to function analysis show a consistent advantage over variables of the more sociological character customary in path analysis by sociologists and psychologists. A bridge has to be built here: the partners of the 'marriage' mentioned in the introduction will gradually have to discover the other's finer nuances in dealing with the explanation especially of earnings. Future household surveys might be enriched with questions of function analysis as applied in business and labour psychology. 


\section{APPENDIXES}

A I. MEANS AND STANDARD DEVIATIONS OF THE VARIABLES

\begin{tabular}{llcc}
\hline Variable & Symbol & Mean & $\begin{array}{c}\text { Standard } \\
\text { deviation }\end{array}$ \\
\hline Family background & $F$ & 41.1 & 10.9 \\
Ability & $A$ & .79 & 2.1 \\
Schooling & $S$ & 10.4 & 2.3 \\
Occupation & OCC & 42.0 & 14.0 \\
Annual earnings (£) & $Y$ & 1651.3 & 873.0 \\
Weekly earnings & $(Y / W)$ & 33.2 & 20.7 \\
Natural log of earnings & $\ln Y$ & 7.30 & .50 \\
Years of experience & $E X$ & 27.5 & 12.3 \\
& & & \\
Dummies & & .0002 & .013 \\
Apprentice & & .78 & .41 \\
Urban resident & & .88 & .33 \\
Married & & .02 & .15 \\
Coloured & & .94 & .24 \\
British & & .10 & .31 \\
Poor health & & & \\
\hline
\end{tabular}

Source: General Household Survey 1972

Men aged 25-64

Sample size 5,578 


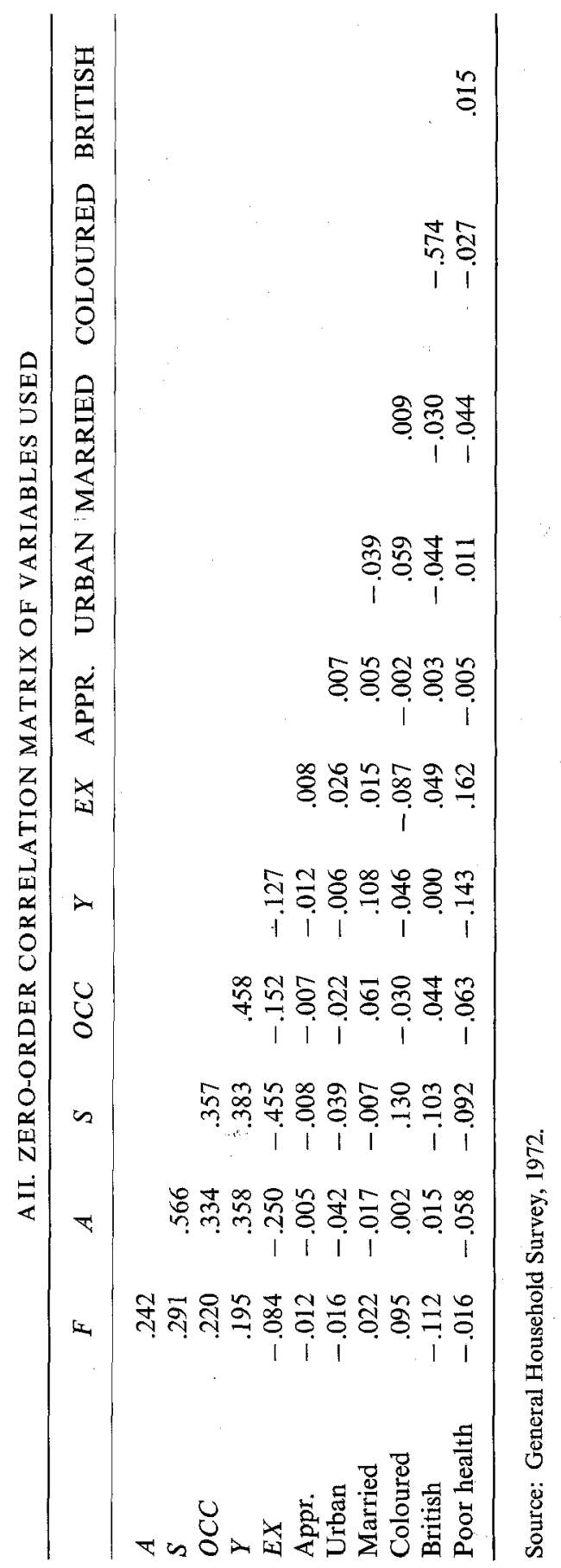




\section{REFERENCES}

Berkouwer, H., J. den Hartog and J. Tinbergen, Alternative Interpretations of Earnings Equations, mimeo, 1978.

Blau, P. M. and O. D. Duncan, American Occupational Structure, New York, 1967.

Bowles, S. and Valerie I. Nelson, 'The Inheritance of IQ and the Inter-generational Reproduction of Economic Inequality,' Review of Economics and Statistics, LVI (1974), pp. 39-51.

Bulcock, J. W., H. Fägerlind and J. Emanuelsson, Education and the Socioeconomic Career II, Institute for the Study of International Problems in Education, Stockholms Universitet, No 10, 1974.

Dronkers, J. and N. de Jong, 'Jencks en Fägerlind op zijn Hollands - Een aanzet voor de studie van relaties tussen milieu, intelligentie, onderwijs, beroep en inkomen,' ('Jencks and Fägerlind the Dutch Way - a Start to Study the Relations Between Environment, Intelligence, Education, Occupation and Income'), Sociologische Gids, XXX (1978/9), pp. 4-30.

Jencks, C., et al., Inequality: A Reassessment of the Effect of Family and Schooling in America, New York-London, 1972.

Mincer, J., 'The Distribution of Labor Incomes: A Survey with Special Reference to the Human Capital Approach,' Journal of Economic Iiterature, VIII (1970), pp. 1-26.

Psacharopoulos, G., 'Family Background, Education and Achievement,' British Journal of Sociology, September 1977.

Tinbergen, J.; 'The Role of Occupational Status in Income Formation,' in: Cramer, J. S., A. Heertje and P. E. Venekamp, eds., Relevance and Precision, Essays in Honour of Pieter de Wolff, Alphen a.d. Rijn/Amsterdam, 1976.

\section{Summary \\ ON THE EXPLANATION OF SCHOOLING, OCCUPATION AND EARNINGS: SOME ALTERNATIVE PATH ANALYSES}

Jencks's well-known sociological path analysis connecting parental socio-economic characteristics and some ability measure of the person investigated with his or her schooling, occupation and income is available for the United States, Sweden and the Netherlands in various versions. For the United Kingdom the analysis has now been applied to the new General Household Survey, supplying over 5000 observations. This article compares the various results and offers a few alternative models, using the American and British data. These alternatives do not offer, in the British case, improvements in variance explained. Moreover, most regression coefficients show wide variations between countries. A suggestion for improvement is derived from a recent study using at least three occupation characteristics. 